This Section of Epidemiology and Psychiatric Sciences regularly appears in each issue of the Journal to describe relevant studies investigating the relationship between neurobiology and psychosocial psychiatry in major psychoses. The aim of these Editorials is to provide a better understanding of the neural basis of psychopathology and clinical features of these disorders, in order to raise new perspectives in every-day clinical practice.

Paolo Brambilla, Section Editor and Michele Tansella, Editor EPS

\title{
The dysregulation profile in children and adolescents: a potential index for major psychopathology?
}

\author{
M. Bellani ${ }^{1 *}$, G. A. L. Negri ${ }^{2}$ and P. Brambilla ${ }^{2,3}$ \\ ${ }^{1}$ Department of Public Health and Community Medicine, Section of Psychiatry and Clinical Psychology, Inter-University Center for Behavioural \\ Neurosciences (ICBN), University of Verona, Verona, Italy \\ ${ }^{2}$ Department of Experimental Clinical Medicine, Inter-University Center for Behavioural Neurosciences (ICBN), University of Udine, Udine, Italy \\ ${ }^{3}$ IRCCS 'E. Medea' Scientific Institute, Udine, Italy
}

\begin{abstract}
We here review the literature on Child Behaviour Checklist-Dysregulation Profile (CBCL-DP) index, which potentially represents a developmental profile of major psychopathology in early adulthood. The understanding of the neural underpinnings of children and adolescents with altered regulation of affect and behaviour may ultimately help in planning strategies to prevent psychiatric syndromes during development.
\end{abstract}

Received 30 November 2011; Revised 12 December 2011; Accepted 13 December 2011

Key words: CBCL, emotional dysregulation, Juvenile Bipolar Disorder.

The Child Behaviour Checklist (CBCL) is a widely used questionnaire in research on developmental psychopathology (Achenbach \& Rescorla, 2001). It is composed of 118 questions filled by the parents and provides $\mathrm{T}$ scores for three general domains (Total, Internalizing and Externalizing problems), eight Empirically Based Syndromes Scales (Anxious/Depressed, Withdrawn/ Depressed, Somatic Complaints, Social Problems, Thought Problems, Attention Problems, Rule-Breaking Behaviour and Aggressive Behaviour) and six Diagnostic and Statistical Manual of Mental Disorders (DSM)-oriented scales (Affective Problems, Anxiety Problems, Somatic Problems, Attention Deficit/ Hyperactivity Problems, Oppositional Defiant Problems and Conduct Problems). In the past few

*Address for correspondence: Dr M. Bellani, Department of Public Health and Community Medicine, Section of Psychiatry and Clinical Psychology, University of Verona, Piazzale L.A. Scuro 10, 37134 Verona, Italy.

(Email: marcella.bellani@univr.it, paolo.brambilla@uniud.it) years, it has been proposed that the sum of $\mathrm{T}$ scores in three Syndromes scales (i.e. Aggressive Behaviour, Anxious/Depressed and Attention Problems) could be used to identify CBCL-Juvenile Bipolar Disorder index (CBCL-JBD index; Biederman et al. 2009). However, the diagnostic value of this index in detecting JBD has been disconfirmed afterwards because of its low sensitivity and specificity (Volk \& Todd, 2007). Recently, the CBCL-JBD index has been renamed as 'CBCL-Dysregulation Profile' (CBCL-DP) index, as it better detects children with 'a persisting deficit of selfregulation of affect and behaviour' (Holtmann et al. 2011). Several studies confirmed that CBCL-DP does not represent an early manifestation of JBD and it is not linked to a specific psychiatric diagnosis (Ayer et al. 2009), rather it is a developmental risk marker of poor overall functioning in adult life (Holtmann et al. 2011, Table 1). In large population-based samples (Ayer et al. 2009; Althoff et al. 2010, Table 1), this index usually indicates a more severe psychopathology, and studies on clinical populations also confirmed these 
Table 1. Summary of the studies described in this review

\begin{tabular}{|c|c|c|c|c|c|}
\hline Study & Sample & Age range & Type of study & $\begin{array}{l}\text { Assessment } \\
\text { and diagnostic }\end{array}$ & Findings \\
\hline $\begin{array}{l}\text { Althoff } e t \text { al. } \\
\quad(2010)\end{array}$ & $\begin{array}{l}1576 \text { subjects population-based } \\
\text { sample }\end{array}$ & $\begin{array}{l}\text { 3-17 at } \\
\text { baseline }\end{array}$ & $\begin{array}{l}\text { Longitudinal } \\
\text { (14 years) }\end{array}$ & CIDI & $\begin{array}{l}\text { CBCL-DP was associated with anxiety and disruptive } \\
\text { behaviour disorders after controlling for co-occurring } \\
\text { disorders in adulthood. }\end{array}$ \\
\hline $\begin{array}{l}\text { Ayer et al. } \\
\text { (2009) }\end{array}$ & $\begin{array}{l}2029 \text { subjects population-based } \\
\text { sample }\end{array}$ & $6-18$ & Psychometric & $\begin{array}{l}\text { CBCL } \\
\text { SES }\end{array}$ & High overlap between CBCL-DP and CBCL-PTSD scale. \\
\hline \multirow[t]{6}{*}{$\begin{array}{l}\text { Biederman } \\
\text { et al. (2009) }\end{array}$} & 204 ADHD & $\begin{array}{l}6-18 \text { at } \\
\text { baseline }\end{array}$ & $\begin{array}{l}\text { Follow-up } \\
\quad \text { (7.4 years) }\end{array}$ & $\begin{array}{l}\text { CBCL } \\
\text { KSADS-E }\end{array}$ & $\begin{array}{l}\text { CBCL-DP predicted subsequent diagnoses of BD, major } \\
\text { depression and conduct disorder. Associated with impaired } \\
\text { psychosocial functioning and psychiatric hospitalization. }\end{array}$ \\
\hline & & & & GAF & \\
\hline & & & & SAICA & \\
\hline & & & & SCID & \\
\hline & & & & SES & \\
\hline & & & & CBCL & \\
\hline \multirow[t]{2}{*}{$\begin{array}{l}\text { Doyle et al. } \\
\quad(2010)\end{array}$} & $\begin{array}{l}765 \text { individuals from } 154 \text { families } \\
\text { enrolled in a linkage study of } \\
\text { ADHD }\end{array}$ & $\begin{array}{l}11.1 \text { mean } \\
\text { age }\end{array}$ & Genetic & CBCL & $\begin{array}{l}\text { Dysregulation profile is highly inheritable. Peaks on } 1 \mathrm{p} 21.1 \text {, } \\
6 \mathrm{p} 21.3 \text { and } 8 \mathrm{q} 21.13 \text { surpassed the threshold for suggestive } \\
\text { linkage. }\end{array}$ \\
\hline & & & & KSADS-E & \\
\hline \multirow[t]{6}{*}{$\begin{array}{l}\text { Halperin et al. } \\
\quad(2011)\end{array}$} & 90 ADHD & $\begin{array}{l}7-11 \text { at } \\
\text { baseline }\end{array}$ & Follow-up & IOWA Conners & $\begin{array}{l}\text { CBCL-DP did not significantly predict Axis I disorders, but it } \\
\text { significantly predicted the presence of a cluster C personality } \\
\text { disorder. }\end{array}$ \\
\hline & & & & DISC & \\
\hline & & & & K-SADS-PL & \\
\hline & & & & SCID-II & \\
\hline & & & & CBCL & \\
\hline & & & & YSR & \\
\hline \multirow[t]{6}{*}{$\begin{array}{l}\text { Holtmann } \\
\text { et al. }(2011)\end{array}$} & $\begin{array}{l}325 \text { young adults at risk for } \\
\text { psychiatric illnesses }\end{array}$ & $\begin{array}{l}0.3 \text { at } \\
\text { baseline }\end{array}$ & $\begin{array}{l}\text { Longitudinal } \\
\text { (19 years) }\end{array}$ & MEI & $\begin{array}{l}\text { CBCL-DP scores in childhood are at increased risk for ADHD, } \\
\text { mood and substance use disorders, suicidality and poorer } \\
\text { overall functioning. }\end{array}$ \\
\hline & & & & SCID-I & \\
\hline & & & & GAF & \\
\hline & & & & SUQ & \\
\hline & & & & FTND & \\
\hline & & & & BDI & \\
\hline
\end{tabular}




\begin{tabular}{|c|c|c|c|c|c|}
\hline \multirow[t]{2}{*}{$\begin{array}{l}\text { Jucksch et al. } \\
\qquad(2011)\end{array}$} & 9024 clinical subjects & $4-18$ & $\begin{array}{l}\text { High DP } v \text {. other } \\
\text { clinical samples }\end{array}$ & GAPD & $\begin{array}{l}\text { CBCL-DP subjects were significantly more impaired and had } \\
\text { more psychosocial adversities than other subgroups. }\end{array}$ \\
\hline & & & & $\begin{array}{l}\text { Psychosocial axis of ICD-10 } \\
\text { (consensus among } \\
\text { clinicians) } \\
\text { CBCL }\end{array}$ & \\
\hline \multirow[t]{6}{*}{$\begin{array}{l}\text { Meyer et al. } \\
\quad(2008)\end{array}$} & $\begin{array}{l}74 \text { offspring of parents with mood } \\
\text { disorders }\end{array}$ & $1.5-7$ & $\begin{array}{l}\text { Longitudinal } \\
\text { (23 years) }\end{array}$ & CAS & $\begin{array}{l}\text { CBCL-DP had significantly lower levels of social and } \\
\text { occupational functioning. They were at risk for anxiety } \\
\text { disorders, ADHD, cluster B personality disorders and BD, } \\
\text { drug abuse and suicidal ideation. }\end{array}$ \\
\hline & 27 controls & & & DICA & \\
\hline & & & & SCID-I & \\
\hline & & & & IPDE & \\
\hline & & & & GAF & \\
\hline & & & & CBCL & \\
\hline \multirow[t]{3}{*}{$\begin{array}{l}\text { Rich et al. } \\
\qquad(2011)\end{array}$} & $20 \mathrm{BD}$ & $8-17$ & $\begin{array}{l}\text { Neuroimaging } \\
\quad(\text { MEG) }\end{array}$ & KSADS-PL & $\begin{array}{l}\text { SMD youth showed greater arousal after negative feedback } \\
\text { than both BD and controls, and they responded to negative } \\
\text { feedback with significantly greater activation of the ACC and } \\
\text { MFG than controls. }\end{array}$ \\
\hline & 20 severe mood dysregulation & & $\begin{array}{l}\text { Affective Posner } \\
\text { Task. }\end{array}$ & CDRS & \\
\hline & 20 controls & & & $\begin{array}{l}\text { YMRS } \\
\text { CGAS }\end{array}$ & \\
\hline \multirow[t]{3}{*}{$\begin{array}{l}\text { Spencer et al. } \\
\quad(2011)\end{array}$} & 197 ADHD & $6-18$ & Group comparison & KSADS-E & $\begin{array}{l}\text { Higher CBCL-DP in ADHD is associated with higher rates of } \\
\text { psychiatric comorbidity and with significant impairment in } \\
\text { social function. }\end{array}$ \\
\hline & 224 controls & & & SAICA & \\
\hline & & & & CBCL & \\
\hline
\end{tabular}

ACC, anterior cingulate cortex; BDI, Beck Depression Inventory; CAS, Child Assessment Schedule; CDRS, Children's Depression Rating Scale; CGAS, Children's Global Assessment Scale; CIDI, Composite International Diagnostic Interview; DICA, Diagnostic Interview for Children and Adolescents; DISC, Diagnostic Interview Schedule for Children; FTND, Fagerström Test for Nicotine Dependence; GAF, Global Assessment of Functioning; GAPD, Global Assessment of Psychosocial Disability; IPDE, International Personality Disorder Examination; KSADS-E, Epidemiological version of Kiddie-Schedule for Affective Disorder and Schizophrenia for Children; MEG, Magneto-Encephalography; MEI, Mannheim Parent Interview; MEL, Munich Events List; SAICA, Social Adjustment Inventory for Children and Adolescents; SES, Socio-Economic Status; SCID, Structured Clinical Interview for DSM-IV; SMD, Severe Mood Dysregulation; SUQ, Substance Use Questionnaire; YMRS, Young Mania Rating Scale; YSR, Youth Self-Report.

MEL

sychosocial axis of ICD-10

clinicians

CBCL

DICA

$\mathrm{CBC}$

than both $\mathrm{BD}$ and controls, and they responded to negative feedback with significantly greater activation of the ACC and 
results. Most of the studies on clinical subjects involved Attention Deficit Hyperactivity Disorder (ADHD). Spencer et al. (2011, Table 1) found that children with ADHD and CBCL-DP were more socially impaired and they had increased probability of comorbid disorders (such as anxiety and disruptive behaviour disorders) compared to non-CBCL-DP ADHD. Consistent findings were reported by follow-up studies on ADHD children (Biederman et al. 2009; Halperin et al. 2011, Table 1).

Studies on heterogeneous clinical populations found results in the same direction. Meyer et al. (2008) analysing data from a 23 years longitudinal study on at-risk youth for psychiatric disorders (i.e. offspring of parents with mood disorders), found that CBCL-DP during childhood is associated with later anxiety disorders, ADHD, cluster-B personality disorders, bipolar disorder (BD), drug abuse and suicidal ideation (Table 1). Similar results were found on 9024 clinical subjects with non-specified psychiatric pathologies (Jucksch et al. 2011) and on 325 children that presented risk factors associated with obstetric complications and psychosocial status (Holtmann et al. 2011, Table 1).

As to the neurobiological bases of this syndrome, so far few studies have investigated the biological and neural substrates of the CBCL-DP. It has been shown that this profile is highly inheritable (Doyle et al. 2010) and that it is associated with genetic regions found in adult BD, schizophrenia, autism and ADHD, like 1p21 (Table 1).

In parallel studies, Rich et al. (2011) using the magnetoencephalography (MEG) compared children with Severe Mood Dysregulation (SMD), characterized by abnormal mood, hyper-arousal and increased reactivity to negative emotional stimuli, being therefore very similar to the CBCL-DP (Leibenluft, 2011), to children with $\mathrm{BD}$ and controls during a Posner Affective Task. This task consists of a modified Posner Task, in which error feedbacks are modified to elicit frustration. The authors found that SMD youth showed greater arousal following negative feedback than both BD and controls, and they responded to negative feedback with significantly greater activation of the anterior cingulate cortex (ACC) and the medial frontal gyrus (MFG) than controls, while BD youth showed dysfunction in the superior frontal gyrus (SFG) and insula (Table 1). It seems therefore that specific cerebral substrates are involved in childhood SMD, thus supporting the hypothesis of a specific syndrome not related to JBD (Leibenluft, 2011).

In conclusion, there is evidence that the CBCL-DP represents a useful index for identifying children and adolescents at risk for psychiatric problems in early adulthood. Given the ease of administration of the CBCL and its widespread use, this could become a powerful and low-cost tool to detect children who need early intervention for the prevention of mental illnesses, reducing the subsequent cost of treatment for psychiatric disorders (Kessler et al. 2009). However, few studies have been carried out so far to explore the potential neurobiological bases of patients with CBCL-DP. More neuroimaging investigations, coupled with neuropsychology and genetics, are therefore expected to further delineate the neural underpinnings of CBCL-DP, which may ultimately help in planning specific strategies to prevent major psychopathology during development.

\section{References}

Achenbach TM, Rescorla LA (2001). Manual for the ASEBA School-Age Forms and Profiles. University of Vermont, Research Center for Children, Youth, and Families: Burlington, VT.

Althoff RM, Verhulst FC, Rettew DC, Hudziak JJ, van der Ende J (2010). Adult outcomes of childhood dysregulation: a 14-year follow-up study. Journal of the American Academy of Child and Adolescent Psychiatry 49, $1105-1116$.

Ayer L, Althoff R, Ivanova M, Rettew D, Waxler E, Sulman J, Hudziak J (2009). Child behavior checklist juvenile bipolar disorder (CBCL-JBD) and CBCL posttraumatic stress problems (CBCL-PTSP) scales are measures of a single dysregulatory syndrome. Journal of Child Psychology and Psychiatry 50, 1291-1300.

Biederman J, Petty C, Monuteaux MC, Evans M, Parcell T, Faraone SV, Wozniak J (2009). The CBCL-pediatric bipolar disorder profile predicts a subsequent diagnosis of bipolar disorder and associated impairments in ADHD youth growing up: a longitudinal analysis. Journal of Clinical Psychiatry 70, 732-740.

Doyle AE, Biederman J, Ferreira MAR, Wong P, Smoller JW, Faraone SV (2010). Suggestive linkage of the CBCL juvenile bipolar disorder phenotype to 1p21, 6p21 and 8q21. Journal of the American Academy of Child and Adolescent Psychiatry 49, 378-387.

Halperin JM, Rucklidge JJ, Powers RL, Miller CJ, Newcorn JH (2011). Childhood CBCL bipolar profile and adolescent/ young adult personality disorders: a 9-year follow-up. Journal of Affective Disorders 130, 155-161.

Holtmann M, Buchmann AF, Esser G, Schmidt MH, Banaschewski T, Laucht M (2011). The child behaviour checklist-dysregulation profile predicts substance use, suicidality, and functional impairment: a longitudinal analysis. Journal of Child Psychology and Psychiatry 52, 139-147.

Jucksch V, Salbach-Andrae H, Lenz K, Goth K, Döpfner M, Poustka F, Freitag CM, Lehmkuhl G, Lehmkuhl U, Holtmann M (2011). Severe affective and behavioural dysregulation is associated with significant psychosocial adversity and impairment. Journal of Child Psychology and Psychiatry 52, 686-695. 
Kessler RC, Aguilar-Gaxiola S, Alonso J, Chatterji S, Lee S, Ormel JT, Üstün TB, Wang PS (2009). The global burden of mental disorders: an update from the WHO World Mental Health (WMH) Surveys. Epidemiologia e Psichiatria Sociale 18, 23-33.

Leibenluft MD (2011). Severe mood dysregulation, irritability, and the diagnostic boundaries of bipolar disorder in youths. American Journal of Psychiatry 168, 129-142.

Meyer SE, Carlson GA, Youngstrom E, Ronsaville DS, Martinez PE, Gold PW, Hakak R, Radke-Yarrow M (2008). Long-term outcomes of youth who manifested the CBCL-pediatric bipolar disorder phenotype during childhood and/or adolescence. Journal of Affective Disorders 113, 227-235.
Rich BA, Carver FW, Holroyd T, Rosen HR, Mendoza JK, Cornwell BR, Fox NA, Pine DS, Coppola R, Leibenluft E (2011). Different neural pathways to negative affect in youth with pediatric bipolar disorder and severe mood dysregulation. Journal of Psychiatric Research 45, 1283-1294.

Spencer TJ, Faraone SV, Surman CB, Petty C, Clarke A, Batchelder H, Wozniak J, Biederman J (2011). Toward defining deficient emotional self-regulation in children with attention-deficit/hyperactivity disorder using the child behaviour checklist: a controlled study. Postgraduate Medicine 123, 50-59.

Volk HE, Todd RD (2007). Does the child behaviour checklist juvenile bipolar disorder phenotype identify bipolar disorder? Biological Psychiatry 62, 115-120. 